\title{
EXPLORANDO POSSIBILIDADES NO ENSINO DA TEMÁTICA LIBERDADE
}

\author{
Raquel Tusi Tamiosso"; Alice Copetti Dalmaso²; Aline Grohe Schirmer Pigatto³
}

\section{RESUMO}

Sabe-se da importância da "Liberdade", considerando todos os aspectos que a envolvem e suas influências na vida dos seres vivos. Considerando que este é um tema relevante e que faz parte da biologia de cada um, o presente trabalho tem como objetivo apresentar as potencialidades de um livreto elaborado para ensinar o tema "Liberdade". A sua elaboração buscou proporcionar aos leitores uma compreensão sobre o tema, por meio do contato com materiais diferenciados, além de promover a divulgação e alfabetização científica. Os materiais utilizados referem-se a reportagens, explanações, músicas e poesias. Acredita-se que os conhecimentos podem ser adquiridos de várias maneiras, utilizando diferentes formas de ensinar e aprender. Nesse sentido, nossa proposta contempla o uso de diferentes linguagens para ensinar, proporcionando a aprendizagem de saberes que versam sobre a Liberdade, vinculados à cultura e à sociedade. Espera-se que o acesso a um material deste tipo, proporcione ao leitor a aprendizagem de conhecimentos específicos, auxilie na alfabetização científica, além de exercer seu pensamento crítico e reflexivo diante de fatos reais, produções culturais e artísticas.

Palavras-chave: Ciência, Divulgação científica, Diversificação de linguagem, Cultura, Comunicação.

Eixo Temático: Educação, Cultura e Comunicação (ECC).

\section{INTRODUÇÃO}

O presente trabalho tem como objetivo relatar as potencialidades de um livreto que visa auxiliar no ensino do tema "Liberdade". Este livreto foi elaborado com algumas especificidades que buscam proporcionar ao leitor uma aprendizagem envolvendo diversas linguagens. Ao abordar o tema, o material traz informações em forma de textos, imagens, músicas e poesias. O motivador de sua produção foi a

\footnotetext{
1 Raquel Tusi Taimosso - Universidade Franciscana - raqueltusitamiosso@gmail.com

2 Alice Copetti Dalmaso - Universidade Federal de Santa Maria - alicedalmaso@gmail.com

${ }^{3}$ Aline Grohe Schirmer Pigatto - Universidade Franciscana - agspigatto@gmail.com
} 
sensibilização dos aprendizes perante o tema, bem como a noção de que as pessoas aprendem de maneiras diferentes e, portanto, torna-se interessante utilizar diferentes linguagens no ensino. Scherer (2015) afirma que cabe ao professor buscar estratégias que contemplem todos os alunos, além de considerar e respeitar o tempo de aprendizagem de cada estudante.

Além disso, um dos propósitos que pretende-se alcançar refere-se à alfabetização científica, especialmente direcionada aos alunos em processo formativo. De acordo com Bueno (2010, p. 5)

A divulgação científica cumpre função primordial: democratizar o acesso ao conhecimento científico e estabelecer condições para a chamada alfabetização científica. Contribui, portanto, para incluir os cidadãos no debate sobre temas especializados e que podem impactar sua vida e seu trabalho, a exemplo de transgênicos, células tronco, mudanças climáticas, energias renováveis e outros itens.

Nesse sentido, considera-se importante divulgar a ciência, para que todos tenham acesso aos saberes, sejam alfabetizados cientificamente e consigam participar de maneira consciente e responsável dos assuntos que permeiam a sociedade. Assim, é importante que haja a divulgação e disseminação de valores científico-culturais visando a alfabetização científica. Essa divulgação da ciência pode ser realizada de diversas maneiras, fazendo uso de diferentes canais e linguagens para alcançar o público-alvo desejado.

Sabe-se da beleza e riqueza de ouvir uma boa música e ler uma boa poesia. É também de muito valor apreciar a leitura de um bom texto. Mas, há preferências indiscutíveis de cada pessoa, inerentes às escolhas ou decisões impostas por terceiros. Nesse sentido, um material educativo que contemple diferentes formas de expressar um determinado assunto, tem potencial para contemplar e incluir as preferências de mais pessoas (neste caso, aprendizes).

Ao mesmo tempo que o livreto visa o ensino e aprendizagem dos estudantes sobre a temática, este também proporciona acesso às diferentes formas de comunicação, tendo em vista que abrange diversas linguagens. Para além, oferece uma conexão com a cultura, convidando os leitores à apreciarem músicas e poesias de vários artistas e autores. É, portanto, algo que envolve o ensino, a comunicação e 
a cultura, juntos em um material.

Outro aspecto positivo refere-se à aproximação de linguagens cotidianas ao conteúdo a ser ensinado, tornando este último mais acessível e muitas vezes familiar (quando já se conhece a música ou poesia apresentada, por exemplo). Nesse contexto, talvez o aluno consiga ressignificar sua interpretação após acrescentar conhecimentos e enxergar novos sentidos ao entrar em contato com o livreto. Da mesma forma, também é possível que o estudante seja sensibilizado a ouvir ou ler com mais atenção músicas e poesias, refletindo sobre sentimentos, emoções, histórias, pensamentos que os "criadores" de tais obras querem passar.

Ressalta-se que o material elaborado não visa direcionar os estudantes a concepções políticas, partidárias ou qualquer outra que leve a uma doutrinação de opiniões. Muito pelo contrário, a intenção é promover uma reflexão LIVRE, que somada aos valores de cada um, provavelmente culminará em novos conhecimentos e conclusões.

Para tratarmos brevemente sobre a liberdade, trouxemos o Artigo 5ㅇ da Constituição Federal, intitulado "Dos direitos e Garantias Fundamentais", que diz o seguinte: "Todos são iguais perante a lei, sem distinção de qualquer natureza, garantindo-se aos brasileiros e aos estrangeiros residentes no País a inviolabilidade do direito à vida, à liberdade, à igualdade, à segurança e à propriedade". Este artigo apresenta diversos incisos especificando os direitos à liberdade, como os seguintes:

Inciso II: "ninguém será obrigado a fazer ou deixar de fazer alguma coisa senão em virtude de lei";

Inciso IX: é livre a expressão da atividade intelectual, artística, científica e de comunicação, independentemente de censura ou licença;

Inciso X: são invioláveis a intimidade, a vida privada, a honra e a imagem das pessoas, assegurado o direito a indenização pelo dano material ou moral decorrente de sua violação.

Outros incisos e mais informações sobre este Artigo de Lei podem ser encontrados no seguinte link: <senado.leg.br/atividade/const/con1988/con1988_15.03.2021/art_5_.asp>.

Tendo em vista o que consta na Lei, podemos considerar este tema 
extremamente importante como essencial. As pessoas precisam saber sobre seus direitos, uma vez que nascem e devem permanecer livres durante suas vidas. Obviamente que, toda essa liberdade tem algumas ressalvas quando trata-se de influenciar na vida de terceiros. Como bem disse John Stuart Mill, "A liberdade de um indivíduo deve ser assim limitada: não deve ser prejudicial aos outros".

Sobre esse "limite" de liberdade, Vieira (2006, p. 22/33) afirma que

[...] tenho liberdade para pensar da maneira que julgo melhor, portanto, tenho liberdade para ser racista, mas se as atitudes que tenho levam-me a cercear a liberdade dos integrantes da sociedade ou, de certa maneira, comprometer o gênero humano, então os direitos de igualdade e fraternidade devem ser impostos a mim. Neste exemplo, racismo não é liberdade de expressão e sim crime inafiançável - é uma atitude que compromete a comunidade e o gênero humano; o indivíduo racista não deve ter liberdade para expressar e divulgar suas ideias, pois a integridade de sua liberdade pode causar muitos danos ao conjunto social (considerando as prerrogativas constitucionais brasileiras, por exemplo)".

Assim, somos livres até o ponto em que não prejudicamos outras pessoas. Ainda sobre a Liberdade, Pecorari (2010, p. 46) argumenta que

[...] é preciso destacar que a liberdade constitui toda a grandeza e a dignidade humana. Só porque é livre o homem pode resistir a todos os estímulos sensíveis, tanto internos quanto externos; pode começar por si mesmo um evento; pode ser legislador absoluto de si mesmo; e pode ser totalmente responsável de tudo aquilo que faz ou deixa de fazer. Por isso, a liberdade caracteriza o ser humano e define sua responsabilidade: ser homem, isto é racional, equivale a ser essencialmente livre e poder agir exclusivamente debaixo da liberdade.

Portanto, a liberdade é parte integrante do ser humano. Somos livres por natureza, e esse é um dos maiores motivos pelos quais precisamos buscar saber sobre liberdade, bem como ensinar os estudantes sobre este importante tema. Essas e outras reflexões que o livreto trará para os leitores, buscando envolver a arte e diferentes formas de comunicação. 


\section{METODOLOGIA}

A proposição deste material foi motivada pela seguinte questão: Quais proposições o professor pode produzir pensando na interlocução entre Ciências, Artes e outras linguagens? Para tanto, estabelecemos uma sequência de materiais visando sensibilizar os leitores na medida que estes o leem. Salientamos que os materiais utilizados não são de nossa autoria. Estes foram selecionados na web e adicionados no livreto, com os respectivos créditos e referências.

Optamos por organizar o livreto da seguinte forma: algumas definições e conceitos sobre liberdade; algumas reportagens sobre acontecimentos reais que ocorreram recentemente e que envolvem o tema liberdade; convite para os leitores escutarem algumas músicas e buscarem refletir sobre as suas letras; convite para os leitores lerem algumas poesias. Ainda, após as músicas e as poesias, há alguns "itens de ação" que foram estruturados com algumas perguntas no intuito de promover reflexões aos leitores. O último "item de ação" presente no livreto convida os leitores a compartilharem algum material (música, poesia, texto, arte) que conheçam e que verse sobre o tema Liberdade.

Todos os materiais selecionados versam sobre o tema "Liberdade", de uma maneira ou de outra. Estes foram organizados em uma apresentação utilizando o site Canva (https://www.canva.com/), buscando potencializar o design.

\section{RESULTADOS E DISCUSSÕES}

A primeira parte do livreto apresenta algumas definições e conceitos importantes que permeiam a Liberdade. Comenta que as pessoas precisam ser livres e sentirem-se livres para serem quem são, viverem o que desejam, serem fiéis a si mesmas, decidirem pelo que desejam, respeitarem os próprios sentimentos. O livreto afirma que somos seres livres, cada qual a sua maneira de ser, pensar e sentir.

A segunda parte do livreto, traz algumas reportagens reais da atualidade que se relacionam com o tema "Liberdade". As buscas pelas reportagens foram realizadas no Google, ao selecionar palavras-chaves sobre o tema. Realizamos capturas de tela de algumas das reportagens encontradas, dispostas na Figura 1. 


\section{QUFN}

Figura 1 - Reportagens que se relacionam com o tema "Liberdade"

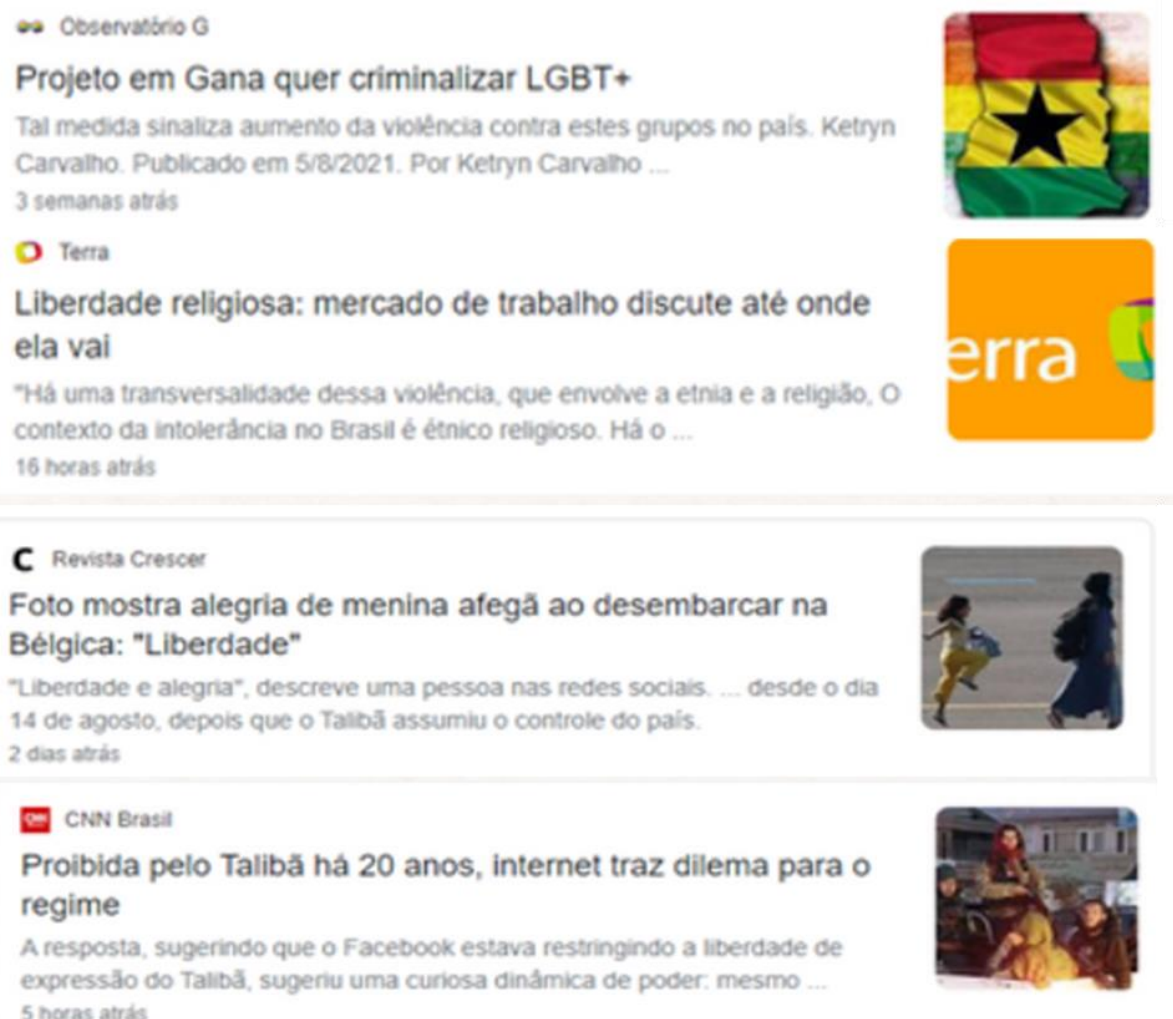

Fonte: PrintScreen de reportagens encontradas no Google.

Ao buscar por notícias relacionadas a este tema, é possível encontrar diferentes situações, negativas e positivas. Encontramos notícias relacionadas ao preconceito com a comunidade LGBTQIA+ (Lésbicas, Gays, Bissexuais, Transexuais, Queer, Intersexuais, Assexuais, e outros), relacionadas ao racismo e intolerância religiosa. Também muitas notícias sobre a violência contra a mulher e restrições impostas por grupos específicos, por exemplo. Apesar de em menor quantidade, encontramos notícias positivas, como iniciativas do governo para enfrentar a violência contra a mulher, maior visibilidade da comunidade LGBTQI+ nas olimpíadas de Tóquio (2020) e "Liberdade" de uma menina afegã ao desembarcar na Bélgica.

Muitas outras notícias e reportagens que se relacionam à Liberdade podem ser encontradas. Selecionamos as primeiras que apareceram, mas as buscas podem ser refeitas (atualizadas) que com certeza aparecerão diversas situações sobre isso. 
$\mathrm{Na}$ terceira parte do livreto, convidamos os leitores a apreciarem algumas músicas de cantores nacionais e internacionais. A primeira música chama-se "Conversa de botas batidas", de autoria da banda Los Hermanos. Primeiro, o livreto orienta ao leitor que escute a música atentamente (Youtube: https://www.youtube.com/watch?v=N3ghu3N-4nY), prestando atenção na sua letra (https://www.letras.mus.br/los-hermanos/67554/). Após isso, o livreto apresenta alguns "Itens de ação", para que o leitor reflita sobre a música. As ações são as seguintes: 1. O que você sentiu? 2. Qual a sua interpretação? 3. O que tem a ver com liberdade? 4. Por qual motivo foi escrita? 5. Busque saber, busque...

Esta música, em especial, possui a história de sua criação divulgada na web. A página seguinte do livreto apresenta o link de acesso à história da música, na qual revela-se o motivo de sua escrita (Link: https://www.letras.mus.br/blog/conversa-debotas-batidas-historia/). Não contaremos aqui o motivo pois queremos instigar você a realizar esse mesmo processo de reflexão e após isso acessar o link com a história real da música. Aproveite este momento para refletir!

O livreto também traz músicas internacionais, como a música "Love" da banda Imagine Dragons (Link: https://www.youtube.com/watch?v=PxlgHSOLO Q) e a música Blowin' in the Wind do músico Bob Dylan (Link: https://www.youtube.com/watch?v=MMFi8uDubsE). Assim como a primeira, essas músicas se relacionam com o tema "Liberdade". Apesar de não conhecermos exatamente as circunstâncias que levaram às suas criações, podemos refletir muito ao compreendermos suas letras.

A quarta parte do livreto traz algumas poesias que se relacionam com o tema "Liberdade". A Figura 2 mostra algumas das nossas seleções, escritas por Clarice Lispector e Guimarães Rosa, respectivamente.

Figura 2 - Algumas poesias que se relacionam com o tema "Liberdade" 


\section{QUFN}

(66 PENSADOR

- Ela é tão livre que um dia será presa.

- Presa por quê?

- Por excesso de liberdade.

- Mas essa liberdade é inocente?

- É. Até mesmo ingênua.

- Então por que a prisão?

- Porque a liberdade ofende.

Clanice dispecton

A água de boa qualidade é como a saúde ou a liberdade: só tem valor quando acaba.

Guimarães Rosa

66 PENSADOR

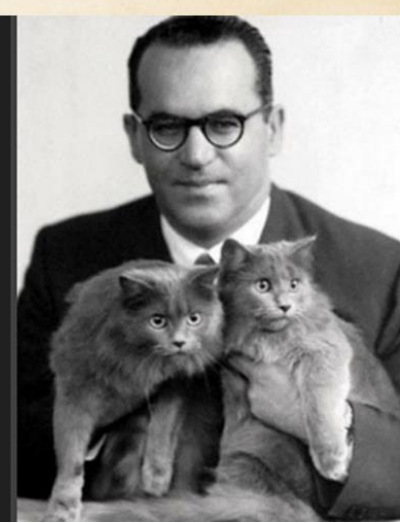

Fonte: <https://www.pensador.com/frase/NTE4NzI0/> $<$ https://www.pensador.com/frase/NjUyMjY1/>, <2021>.

Encontramos diversas poesias nacionais que versam sobre este tema (aqui adicionamos apenas duas em função do espaço). Deixamos os leitores livres para interpretarem as poesias, refletirem sobre elas e agregarem mais conhecimentos. Acreditamos que com este exercício, os leitores serão capazes de aprender mais sobre a liberdade, bem como serão estimulados a refletirem sobre aquilo que escutam e que leem, internalizando sentimentos, emoções e expressões. Certos sentimentos, inclusive, podem ser compartilhados entre autor/artista e leitor. Como dizia a poetisa Therezinha Lucas Tusi, em seu poema Afinidades (1984):

"O papel é o lenço branco em que o poeta enxuga o pranto. Lenço, tão pessoal, não se empresta!

Mas se torna universal quando o leitor se encontra na dor do poeta".

Nesse sentido, o ensino pode e deve contemplar obras artísticas em suas ações, diversificando suas linguagens e proporcionando acesso a diferentes saberes através da cultura! 


\section{CONCLUSÃO}

O presente trabalho tem como objetivo relatar as potencialidades de um livreto que visa auxiliar no ensino do tema "Liberdade". O livreto contempla diferentes materiais, como músicas, poesias e reportagens, que relacionam-se com o tema em questão.

Apesar deste material ainda não ter sido publicado ou mesmo aplicado em sala de aula, acreditamos que a ideia precisa ser compartilhada imediatamente. É uma maneira de trabalhar assuntos que envolvem a Biologia e as Ciências Humanas, por exemplo, de uma forma diferente da convencional.

Ao mesmo tempo em que há o estímulo para aprendizagem de conhecimentos relacionados à ciência, estimulando a divulgação e alfabetização científica, há um incentivo à apreciação da cultura e da arte, possibilitando uma aprendizagem diferenciada. Existe uma diversidade de músicas, poesias e mesmo notícias que podem ser exploradas para estudo de um determinado tema. Essa prática proporciona, muitas vezes, momentos mais prazerosos e cativantes no ensino.

Portanto, com acesso a um material deste tipo, o leitor aprenderá conhecimentos específicos, terá acesso à saberes relacionados à ciência e sociedade, além de exercer seu pensamento crítico e reflexivo diante de fatos reais, produções culturais e artísticas.

\section{AGRADECIMENTOS}

O presente trabalho foi realizado com apoio da Coordenação de Aperfeiçoamento de Pessoal de Nível Superior - Brasil (CAPES).

\section{REFERÊNCIAS}

BUENO, W. Comunicação científica e divulgação científica: aproximações e rupturas conceituais. Revista Informação \& Informação, v. 15, n. esp., p. 1-12, 2010. Disponível em: https://www.brapci.inf.br/index.php/article/download/14078. Acesso em: 28. jul. 2021. 
PECORARI, F. O conceito liberdade em Kant. Revista ética e filosofia política, $\mathrm{n}$. 12, v. 1, 2010, p. 44-59. Disponível em:

<https://www.ufjf.br/eticaefilosofia/files/2010/04/12_1_pecorari.pdf>. Acesso em: 27 ago. 2021.

SCHERER, R. P. "Cada um aprende de um jeito": das adaptações às flexibilizações curriculares. Dissertação (Mestrado em Educação) - Programa de Pós-graduação em Educação, Universidade do Vale do Rio dos Sinos. São Leopoldo, p. 173. 2015.

TUSI, T. L. Afinidades. Porto Alegre: Movimento, 1984.

VIEIRA, E. P. P. Biologia, direitos humanos e educação: diálogos necessários. Dissertação (Mestrado em Educação em Ciências e Matemática) - Núcleo Pedagógico de Apoio ao Desenvolvimento Científico, Universidade Federal do Pará. Belém, p. 94. 2006. 